\title{
PRONAF E EMPODERAMENTO DAS MULHERES RURAIS. UMA ANÁLISE DAS DIMENSÕES ECONÔMICA, SOCIAL E POLÍTICA
}

\author{
PRONAF AND EMPOWERMENT OF RURAL WOMEN. ANALYSIS FROM \\ ECONOMIC, SOCIAL AND POLITICAL DIMENSIONS
}

\section{PRONAF Y EMPODERAMIENTO DE MUJERES RURALES. ANÁLISIS DE DIMENSIONES ECONÓMICA, SOCIAL Y POLÍTICA}

\author{
Alessandra Maria da Silva ${ }^{1}$ \\ http://orcid.org/0000-0002-6640-7925 \\ Niraldo José Ponciano ${ }^{2}$ \\ http://orcid.org/0000-0002-8663-5458 \\ Paulo Marcelo de Souza ${ }^{3}$ \\ http://orcid.org/0000-0002-5788-915X
}

Submissão: 29/05/2020 / Aceito: 19/07/2020.

\begin{abstract}
Resumo
O Programa Nacional de Fortalecimento da Agricultura Familiar (Pronaf) prevê a priorização dos projetos de beneficiárias mulheres, como forma de favorecer o desenvolvimento da sua autonomia e contribuir para seu empoderamento. Este trabalho teve por objetivo conhecer o efeito do acesso ao crédito Pronaf sobre a autonomia econômica das mulheres beneficiárias e os impactos para o seu empoderamento nas dimensões econômica, social e política. Como arcabouço teórico, considerou-se gênero como categoria de análise. A pesquisa empírica do tipo qualitativa foi realizada nos municípios de Nova Venécia e de Rio Bananal, no estado do Espírito Santo, durante o ano de 2017. Uma amostra representativa de 55 mulheres tomadoras de crédito Pronaf entre os anos de 2013 a 2016 foi submetida a um roteiro de entrevista semiestruturada, abordando, entre outras questões, as relações familiares, o processo decisório, a experiência com o Pronaf e os fatores de mudança. As entrevistas foram transcritas, sistematizadas e submetidas à análise de conteúdo. Apesar de o acesso ao Pronaf ter contribuído para a ampliação da renda familiar, o empoderamento econômico, social e político das mulheres foi prejudicado pelas relações desiguais de gênero presentes nas famílias e na própria sociedade.
\end{abstract}

Palavras-chave: Pronaf. Mulheres rurais. Dimensões do empoderamento. Autonomia.

\begin{abstract}
The National Program for Strengthening Family Farming (Pronaf) provides for the prioritization of projects of women beneficiaries, as a way to promote the development of their autonomy and contribute to their empowerment. This study aimed to understand the effect of access to Pronaf credit on the economic autonomy of women beneficiaries and the impacts on their empowerment in the economic, social and political dimensions, using gender analisis framework. The qualitative empirical research was carried out in the municipalities of Nova Venécia and Rio Bananal, in the state of

\footnotetext{
${ }^{1}$ Doutora em Produção Vegetal (UENF), Agente de Extensão em Desenvolvimento Rural do Instituto Capixaba de Pesquisa, Assistência Técnica e Extensão Rural (INCAPER). Linhares-ES. E-mail: alessandra@incaper.es.gov.br.

${ }^{2}$ Doutor em Economia Rural (UFV), professor da Universidade Estadual do Norte Fluminense Darcy Ribeiro (UENF). Campos dos Goytacazes-RJ. E-mail: njponciano@gmail.com.

${ }^{3}$ Doutor em Economia Rural (UFV), professor da Universidade Estadual do Norte Fluminense Darcy Ribeiro (UENF). Campos dos Goytacazes-RJ. E-mail: pmouza@uenf.br.
} 
Espírito Santo, Brazil, during 2017. A representative sample of 55 women underwent a semistructured interview script, addressing, among other issues, family relationships, decision making, experience with Pronaf, and change factors. The interviews were transcribed, systematized and subjected to content analysis. Although access to Pronaf contributed to the expansion of family income, women's economic, social and political empowerment was undermined by unequal gender relations in families and society itself.

Keywords: Pronaf. Rural women. Empowerment’s dimensions. Autonomy.

\section{Resumen}

El Programa Nacional para el Fortalecimiento de la Agricultura Familiar (Pronaf) establece la priorización de proyectos para mujeres, como una forma de favorecer el desarrollo de su autonomía y contribuir a su empoderamiento. Este estudio tuvo como objetivo comprender el efecto del acceso al crédito de Pronaf en la autonomía económica de las mujeres y los impactos en su empoderamiento en las dimensiones económica, social y política. Como marco teórico, el género se consideró como una categoría de análisis. La investigación empírica cualitativa se llevó a cabo en las ciudades de Nova Venécia y Río Bananal, Espírito Santo, Brasil, durante el año 2017. El estudio se hizo mediante la realización de entrevistas semiestructuradas a una muestra representativa de 55 mujeres, centrándose en: las relaciones familiares, el proceso de toma de decisiones, la experiencia con Pronaf y los factores de cambio. Las entrevistas fueron transcritas, sistematizadas y sometidas a análisis de contenido. Aunque el acceso a Pronaf contribuyó a la expansión del ingreso familiar, el empoderamiento económico, social y político de las mujeres se vio obstaculizado por las relaciones de género desiguales presentes en las familias y en la sociedad misma.

Palabras-clave: Pronaf. Mujeres Rurales. Dimensiones de empoderamiento. Autonomía.

\section{INTRODUÇÃO}

A reprodução social e econômica da agricultura familiar teve forte apoio das políticas públicas destinadas ao meio rural, em especial das políticas de crédito, desde meados da década de 1990. No entanto, o processo de construção dessas políticas não atendeu, efetivamente, a diversidade cultural e produtiva, as formas de organização e de reprodução das unidades familiares, o que contribuiu para a desigualdade de acesso a elas.

Historicamente, os serviços públicos de assistência técnica e extensão rural (ATER) foram destinados à família ou à unidade de produção familiar, porém, reproduzindo a lógica de exclusão ao tomar como unidade de referência de planejamento e de ação o homem como chefe de família. Como consequência, as políticas agrícolas e agrárias não visualizaram o trabalho produtivo das mulheres, secundarizando-o e descaracterizando-o como mera “ajuda" aos homens (HERRERA, 2019; SILIPRANDI, 2015). É essa forma de olhar a organização do trabalho que serviu de referência, no passado, para as políticas de desenvolvimento rural, incluindo os serviços de assistência técnica e extensão rural (MORAES et al. 2018).

A partir do reconhecimento da desigualdade existente entre homens e mulheres rurais, as políticas públicas buscaram, entre outros resultados, estimular a geração de renda 
própria e ocupação para as mulheres rurais em atividades agrícolas e não agrícolas. $\mathrm{O}$ desenvolvimento da autonomia econômica das mulheres rurais pode contribuir para a redução da pobreza do campo, além da possibilidade de romper com o padrão de divisão sexual do trabalho, ampliar o poder de decisão das mulheres e promover o seu empoderamento econômico e social, como parte do processo de desenvolvimento rural (BUTTO et al., 2014; SEN, 2000).

Para se alcançar a autonomia econômica feminina, há a necessidade de facilitar o seu acesso à terra, ao crédito e à assistência técnica (BUTTO et al., 2014), daí as ações articuladas nos programas e políticas para mulheres rurais. Quanto ao crédito, atribui-se a necessidade de financiamento da produção agropecuária ou não agropecuária como ponto de partida para o desenvolvimento das atividades geradoras de renda. Dessa forma, os programas de crédito rural, como o Programa Nacional de Fortalecimento da Agricultura Familiar (Pronaf), apresentam-se como ferramentas no processo de desenvolvimento rural, partindo-se da premissa de que o financiamento para a adoção de tecnologias em projetos de inversão e de custeio resultam na ampliação da produtividade e, consequentemente, da renda, contribuindo para a melhoria da qualidade de vida (HERNANDEZ, 2009).

$\mathrm{O}$ acesso ao crédito pelas mulheres rurais pode ampliar as oportunidades de investimento, de geração de renda e de participação em espaços públicos, estendendo o seu conhecimento e as suas relações sociais. Esse maior envolvimento com a vida pública e com os novos desafios contribui para aumentar o capital social ${ }^{4}$ das mulheres, que Specht (2019) considera fundamental para o desenvolvimento da autonomia. Mas, para que isso ocorra, há a necessidade de mudança da postura da mulher diante da família e da sociedade, quanto da própria dinâmica familiar, nas questões de conscientização, participação e acesso e controle de recursos. E esse processo de mudança não é homogêneo, nem linear, variando segundo a mulher e o contexto em que vive (DEERE e LEÓN, 2002).

Os programas de crédito com foco em gênero devem contribuir para promover a condição de agentes de transformação das mulheres, não permanecendo como agentes passivos de mudanças. Desta forma, se o Pronaf busca contribuir para a igualdade de gêneros ao orientar a priorização do crédito para mulheres, além da linha de crédito específica Pronaf

\footnotetext{
${ }^{4}$ Pode-se conceituar capital social como as relações duráveis estabelecidas entre as pessoas, que contribuem para o desenvolvimento de laços de confiança, favorecendo a coesão necessária para facilitar ações coordenadas e aumentar a eficiência da sociedade (PUTNAM, 1993).
} 
Mulher, questionam-se as condições em que se desenvolvem as autonomias econômica, social e política das mulheres rurais, sendo a família um espaço de conflito de poderes.

Este trabalho teve por objetivo conhecer o efeito do acesso ao crédito Pronaf sobre a autonomia econômica de mulheres dos municípios de Nova Venécia e de Rio Bananal, Espírito Santo, e os impactos para o seu empoderamento econômico, social e político.

\section{METODOLOGIA}

A pesquisa utilizou a abordagem relacional, considerando gênero como categoria analítica. A metodologia adotada para este estudo foi qualitativa, pois os métodos enfatizaram especificidades de fenômenos, permitindo captar dados subjetivos, não facilmente articulados, como atitudes, motivos e pressupostos (HAGUETTE, 2010).

A pesquisa empírica foi realizada no ano de 2017, nos municípios de Nova Venécia e de Rio Bananal, localizados nas regiões norte do estado do Espírito Santo, respectivamente. As unidades de análise da pesquisa foram as mulheres rurais beneficiárias do Pronaf entre os anos de 2013 e 2016, identificadas por meio de um levantamento realizado junto às consultorias locais, totalizando uma população de 265 mulheres.

Para a composição da amostra foi utilizado o método probabilístico de amostragem estratificada proporcional, considerando $10 \%$ de erro e $90 \%$ de Intervalo de Confiança, totalizando 55 mulheres na amostra.

Por meio da aplicação de roteiros de entrevistas semiestruturadas, foram estudados o perfil das mulheres tomadoras de crédito Pronaf, as suas relações sociais; as experiências no processo de decisão e aplicação dos recursos do Pronaf; as relações das mulheres com os agentes externos; a participação dessas mulheres no processo de divisão do trabalho; suas contribuições na diversificação da produção, geração de trabalho e renda nas unidades produtivas familiares e identificadas as estratégias de empoderamento e de organização utilizadas pelas mulheres agricultoras para o acesso às políticas públicas.

As entrevistas foram gravadas em áudio sob autorização das mulheres e contemplaram as dimensões social, econômica e política do empoderamento, sob os quais se definiram os indicadores (MALHOTRA et al., 2002; SEN, 2000). As entrevistas foram transcritas, sistematizadas e submetidas à análise de conteúdo (BARDIN, 1977). 
Para a análise do impacto dos indicadores de empoderamento considerou-se a condição que as mulheres e suas famílias apresentavam antes do acesso ao Pronaf e as mudanças ocorridas desde então, sendo identificadas no momento da entrevista. O impacto do acesso ao Pronaf no empoderamento das mulheres rurais foi calculado a partir da adaptação do método utilizado por Demattê Filho et al. (2014) e Rodrigues, Pimenta e Casarini. (2016) para análise de impactos ambientais. Os 25 indicadores foram organizados em planilhas eletrônicas nas três dimensões de empoderamento: econômico, social e político, os quais foram verificados pelo instrumental analítico (análise de conteúdo) dos dados obtidos nas entrevistas e categorizados.

Foram construídas matrizes de ponderação para cálculo dos índices de impacto. Calculou-se um fator de ponderação atribuindo o mesmo peso para os indicadores de cada dimensão, cujo somatório resultou igual a 1,0. De posse dos dados obtidos na análise de conteúdo, para cada indicador, estabeleceu-se uma escala de nível de ocorrência que variou de 1 a 3, conforme apresentado por Silva (2019).

Ainda, para cada indicador, estabeleceu-se uma escala de coeficiente de mudança que variou de zero a 2. Assim, o índice de impacto de cada indicador se deu pelo somatório do produto do valor da escala de nível de ocorrência de cada unidade de análise pelo valor do coeficiente de mudança a ela atribuído e multiplicado pelo fator de ponderação daquele indicador:

$$
I=k \sum(N \times C)
$$

Onde:

I = índice de impacto

$\mathrm{k}=$ fator de ponderação

$\mathrm{N}$ = nível de ocorrência

$\mathrm{C}=$ coeficiente de mudança

A partir do cálculo do índice de impacto de cada indicador, calculou-se o índice médio entre os indicadores de cada dimensão, sendo este utilizado para comparar o impacto do Pronaf em relação ao índice máximo de cada dimensão e entre as dimensões de empoderamento.

É importante observar que, segundo Malhotra et al. (2002) e Mosedale (2005), não há empoderamento absoluto, sendo o resultado desta análise apenas uma proposta para verificação das dimensões mais vulneráveis, que necessitam de intervenções mais imediatas. 


\section{RESULTADOS E DISCUSSÃO}

\section{As dimensões do empoderamento como objeto de avaliação do impacto das políticas de crédito}

O termo empoderamento, ou empowerment, apresenta diversos conceitos, dependendo do contexto em que é analisado. As agências governamentais visualizam o empoderamento feminino como um instrumento de desenvolvimento, com foco em autonomia financeira para redução da pobreza, como democracia ou acesso a direitos. Enquanto que, para o movimento feminista, o empoderamento é o processo da conquista da autonomia, um meio de libertação da opressão patriarcal (SARDENBERG, 2006).

Para Mosedale (2005), o empoderamento é entendido como uma aquisição de poder, de fortalecimento de um indivíduo ou de um grupo, antes desprovido de poder. Esse poder está relacionado à sua capacidade de tomada de decisão para transformação da própria vida.

As definições de empoderamento geralmente incluem a ideia de pessoas desenvolvendo autonomia, tomando decisões sobre questões importantes em suas vidas e sendo capaz de externá-las. As etapas de reflexão, análise e ação estão envolvidas nesse processo, que podem acontecer individualmente ou coletivamente (MOSEDALE, 2005).

Os mediadores podem atuar como facilitadores do empoderamento na medida em que se criam condições favoráveis para o desenvolvimento da autonomia, mas não podem fazê-lo acontecer. Da mesma forma, se os agentes criam e facilitam as condições para o empoderamento, é necessário que, antes, as pessoas tomem consciência e empoderem-se por si mesmas (MOSEDALE, 2005).

$\mathrm{O}$ empoderamento não é um processo linear, não tem um início nem um fim delimitados e não acontece de maneira igual entre as mulheres, devido à diversidade cultural, econômica, social e política existente entre elas (KABEER, 2012). Esse processo ocorre de maneira diferente para cada indivíduo ou grupo de indivíduos, conforme o contexto em que vive, sua história de vida e a posição de subordinação que ocupa, seja ela em nível pessoal, familiar, comunitário, regional ou global (DEERE e LEÓN, 2002).

Considerando a existência de relações desiguais de gênero, o empoderamento das mulheres pode ser entendido como um processo de superação da desigualdade de gênero. A 
dimensão econômica é importante nesse processo, devendo ser uma estratégia política, mas não a única, uma vez que a privação da autonomia econômica gera privação da autonomia social que, da mesma forma, limita a autonomia econômica (SEN, 2000).

O respeito e o bem-estar das mulheres são diretamente influenciados por variáveis, como o potencial das mulheres de ter autonomia financeira por meio da renda independente, ter direitos de propriedade, ter acesso à educação e "participar como pessoas instruídas nas decisões dentro e fora da família” (SEN, 2000, p. 222). Isso contribui positivamente para fortalecer a voz ativa e a condição de agente das mulheres por meio da independência e ganho de poder (SPECHT, 2019).

Ter renda própria produz impacto sobre a melhora da posição social da mulher dentro da família e, também, na sociedade, pois torna visível e, portanto, reconhecida a sua contribuição para a prosperidade da família. Além disso, a mulher passa a ter mais voz ativa, já que depende menos dos outros (SEN, 2000, SPECHT, 2019).

Segundo Malhotra et al. (2002), o papel do gênero no desenvolvimento não pode ser compreendido somente no contexto econômico, como também no sociocultural e político, nos quais o desenvolvimento ocorre. Para a autora, o conceito de empoderamento só tem significado dentro desses contextos. Ela sintetiza e relaciona as dimensões de empoderamento de mulheres mais comumente usadas por diversos autores do tema, sendo elas: econômica, sociocultural e política.

No plano individual, a dimensão econômica envolve a análise da contribuição relativa da renda das mulheres nas finanças da família e seu acesso e controle sobre os recursos familiares. Em nível local, refere-se ao acesso das mulheres ao emprego, posse de bens e terras, acesso ao crédito, acesso às instituições bancárias e comerciais e mercados (MALHOTRA et al., 2002).

A dimensão sociocultural envolve, em nível individual, a liberdade de mobilidade, a consciência de gênero e das desigualdades submetidas, bem como as mudanças na ordem patriarcal estabelecida e o acesso à educação. Em nível local, observa-se a visibilidade das mulheres na comunidade, seu acesso aos espaços sociais como grupos comunitários, redes sociais. Já a dimensão política se refere ao conhecimento dos próprios direitos, bem como a mobilização para exercê-los; ao conhecimento das políticas públicas, e como acessá-las, e ao exercício da cidadania (MALHOTRA et al., 2002). 
A partir da análise desses indicadores de empoderamento torna-se possível verificar se o Pronaf e a forma como ele é operacionalizado de fato contribuem para a mudança nas relações sociais das beneficiárias. A construção da condição de agente dessas mudanças na busca pelo próprio bem-estar e das pessoas em seu entorno, é um indicativo de processo de obtenção de poder, de desenvolvimento da capacidade de assumir o controle da própria vida.

\section{O acesso ao Pronaf: transformações para o empoderamento}

Neste estudo, as mulheres acessaram o Pronaf para a modalidade de investimento em lavouras de café Conilon em 63,6\% dos casos, além da pimenta-do-reino (23,6\%) e outras atividades tradicionais na região. A principal linha de crédito acessada foi o Pronaf Mais Alimentos (25,5\%), seguido do Pronaf Mulher (16,4\%) e outras (5,4\%), embora, 52,7\% das mulheres não soubessem informar a linha de crédito ou a finalidade do financiamento.

Observou-se que $26 \%$ dos projetos foram acessados pelas mulheres para atender à necessidade de um membro da família, do sexo masculino, que havia alcançado o limite de sua capacidade de crédito ou que não se enquadrava nos critérios ${ }^{5}$ para obtenção do crédito Pronaf. Além disso, 52,7\% das mulheres entrevistadas não participaram da gestão dos recursos financeiros, repassando-os para o marido, pai, filho ou irmão gerir. Somente as mulheres sem companheiro e que não sofriam influência masculina em suas decisões, se envolveram completamente no processo. E, destas, nenhuma acessou o Pronaf Mulher.

A decisão de acessar ou não o programa depende, muitas vezes, do aval dos maridos, evidenciando o limite da autonomia das mulheres. Geralmente, os projetos são construídos pensando-se na lógica de divisão sexual do trabalho, tendo em vista a continuidade das atividades complementares que as agricultoras já desenvolviam anteriormente, o que também impõe limites ao processo de mudanças nas relações de gênero nas unidades produtivas familiares (HERNÁNDEZ, 2009).

Esse comportamento também foi observado em outros estudos com o Pronaf (FERNANDES, 2013; HERNÁNDEZ, 2009; SPANEVELLO et al., 2016), onde a decisão do investimento geralmente é feita pelos homens, considerados "chefes da família". Ocorre

\footnotetext{
${ }^{5}$ Conforme o Manual de Crédito Rural (2014), o Pronaf pode ser acessado por agricultores e agricultoras familiares portadores da Declaração de Acesso ao Pronaf (DAP), que apresentem um projeto de viabilidade técnica e econômica de aplicação do recurso em atividades agropecuárias, cujo valor de financiamento não ultrapasse a capacidade máxima de endividamento individual de $\mathrm{R} \$ 165.000,00$.
} 
uma reconfiguração na divisão sexual do trabalho e no processo de produção, sem haver, necessariamente, uma mudança na forma de gestão das atividades e de utilização dos recursos. Ou seja, o Pronaf contribuiu para a complementação da renda familiar, mas não emancipou ou empoderou as mulheres rurais. $\mathrm{O}$ incremento financeiro é necessário e importante, mas não é suficiente para alterar as estruturas hierárquicas presentes nas famílias e na sociedade (HERRERA, 2019).

Sob a perspectiva do processo de empoderamento proposta por Malhotra et al. (2002) e Sen (2000), analisou-se a situação das mulheres a partir do acesso ao crédito Pronaf, mas considerando a sua história pregressa, como forma de comparar as mudanças ocorridas. Investigou-se a ampliação do seu poder de transformar a própria vida, se houve o desenvolvimento da capacidade de fazer suas próprias escolhas e definir suas próprias prioridades, seus próprios interesses. Os resultados deste estudo apontam que o empoderamento não foi homogêneo entre as mulheres, devido aos diferentes contextos e diferentes histórias de vida. Mas, é possível afirmar que o impacto principal do acesso ao crédito Pronaf foi sobre o empoderamento econômico (Tabela 1 e Figura 1).

Nessa dimensão, os indicadores que influenciaram positivamente no impacto foram a autonomia sobre a renda pessoal e o bem-estar da família. Há de se observar que muitas mulheres possuem renda própria oriunda de ocupações não agrícolas (ONA), como faxineiras e comerciárias, ou de rendas não agrícolas (RNA), como aposentadorias. Portanto, não se pode afirmar que o impacto positivo no empoderamento econômico de todas as mulheres ocorreu devido ao acesso ao crédito. Mas, pode-se afirmar que nos casos em que as mulheres tiveram autonomia para gerir a atividade financiada pelo Pronaf, o acesso ao crédito contribuiu para o aumento da renda pessoal. Foi possível observar, também, que o acesso à renda pessoal é, de fato, um importante gerador de empoderamento econômico (Tabela 1). 
Tabela 1 - Distribuição dos valores obtidos para os Índices Médios de Impacto (IMI) por variável (indicadores de mudança) e dos Índices de Impacto do Empoderamento (IIE), a partir dos indicadores das dimensões econômica, política e social no empoderamento das mulheres beneficiárias do Pronaf em Nova Venécia e Rio Bananal, ES, em 2017

\begin{tabular}{|c|c|c|c|}
\hline Dimensões & Variáveis & IMI & IIE \\
\hline \multirow{10}{*}{$\begin{array}{c}\text { Econômica } \\
\left(\mathrm{k}^{*}=0,1\right)\end{array}$} & Autonomia sobre a renda & 0,08 & \multirow{10}{*}{1,47} \\
\hline & Bem-estar & 0,40 & \\
\hline & Capacidade de negociação com atores externos & 0,13 & \\
\hline & Conhecimento técnico gerencial & 0,08 & \\
\hline & Diversificação da propriedade & 0,24 & \\
\hline & Divisão sexual do trabalho & $-0,05$ & \\
\hline & Gestão dos recursos produtivos & 0,13 & \\
\hline & Mobilização de recursos & 0,24 & \\
\hline & Participação na tomada de decisão & 0,08 & \\
\hline & Posse da terra & 0,14 & \\
\hline \multirow{5}{*}{$\begin{array}{c}\text { Política } \\
(\mathrm{k}=0,2)\end{array}$} & Capacidade de estabelecer redes de apoio & 0,12 & \multirow{5}{*}{0,52} \\
\hline & Participação em cargos de diretoria & 0,01 & \\
\hline & Participação em organizações & 0,07 & \\
\hline & Participação em outras políticas públicas & 0,11 & \\
\hline & Relacionamento com outros atores sociais e políticos & 0,21 & \\
\hline \multirow{10}{*}{$\begin{array}{c}\text { Social } \\
(\mathrm{k}=0,1)\end{array}$} & Acesso à assistência técnica & 0,06 & \multirow{10}{*}{0,99} \\
\hline & Acesso à informação e conhecimento técnico & 0,07 & \\
\hline & Capacidade de expor ideias e se motivar & 0,05 & \\
\hline & Consciência de gênero & 0,02 & \\
\hline & Desenvolvimento da autoestima & 0,31 & \\
\hline & Desenvolvimento da capacidade de agência & 0,10 & \\
\hline & Mobilidade física para relacionamentos sociais & 0,06 & \\
\hline & Participação social & 0,23 & \\
\hline & Participação em formações e capacitações & 0,06 & \\
\hline & Relações de gênero na família & 0,03 & \\
\hline
\end{tabular}

* $\mathrm{k}=$ fator de ponderação

Fonte: dados da pesquisa

Paralelamente ao aumento da autonomia sobre a renda pessoal, o segundo indicador que mais impactou positivamente essa dimensão foi o de bem-estar da família. As mulheres com autonomia financeira tendem a investir na qualidade de vida dos seus, sendo esse o primeiro fator a ser considerado pela mulher quando ela tem acesso a recursos financeiros.

Já o indicador que mais influenciou negativamente no empoderamento econômico das mulheres foi a permanência da divisão sexual do trabalho, que não apresentou mudanças para $85,5 \%$ das mulheres. Essas mulheres não conseguiram ampliar sua autonomia econômica devido às relações desiguais de gênero que limitam as capacidades das mulheres, bem como a dupla ou tripla jornada de trabalho apresentadas por elas. De fato, as mulheres não restringem seu trabalho na esfera reprodutiva, mas fluem de uma esfera à outra (produtiva), atendendo às necessidades dos filhos, do marido, familiares, animais e plantas que compõem a casa (HERRERA, 2019). 
As mulheres, para conseguirem ter autonomia sobre a própria renda, tendem a ingressar em atividades não agrícolas, de forma a não concorrer com os homens nas atividades agropecuárias comerciais desenvolvidas nas unidades produtivas. Porém, a sua função reprodutiva não é compartilhada com os homens da família, cabendo a elas o acúmulo de atividades, comprometendo a sua saúde, bem como o seu tempo para desenvolver outras dimensões do empoderamento.

Outros indicadores que devem ser analisados em seu impacto no empoderamento econômico das mulheres são a diversificação da propriedade e a participação das mulheres na gestão da propriedade. O primeiro apresentou relativo impacto positivo, porém não em consequência do acesso ao crédito, mas pelas atividades já desenvolvidas anteriormente pelas mulheres. Houve, de fato, uma tendência de as mulheres financiarem as atividades normalmente executadas pelos homens, tanto por uma escolha pessoal, mas, principalmente, para atender à necessidade de crédito do homem, mantendo-se o investimento em atividades zoneadas, mais facilmente aprovadas em projetos de crédito.

Quanto à baixa participação das mulheres na gestão da propriedade, trata-se tanto do sentimento de insegurança das mulheres a respeito do conhecimento de técnicas produtivas e gerenciais, quanto da própria discriminação da família e dos mediadores, que tendem a duvidar da capacidade produtiva das mulheres rurais, excluindo-as do acesso ao conhecimento técnico gerencial. Portanto, pode-se afirmar que a ideia da inferioridade das mulheres em relação aos homens se mantém nos símbolos e valores socialmente construídos, interferindo significativamente no desenvolvimento das capacidades das mulheres. 
Figura 1 - Representação esquemática do impacto do acesso ao Pronaf pelas mulheres de Nova Venécia e de Rio Bananal, ES, em 2017, a partir das dimensões do empoderamento propostas por Malhotra et al. (2002) e Sen (2000)

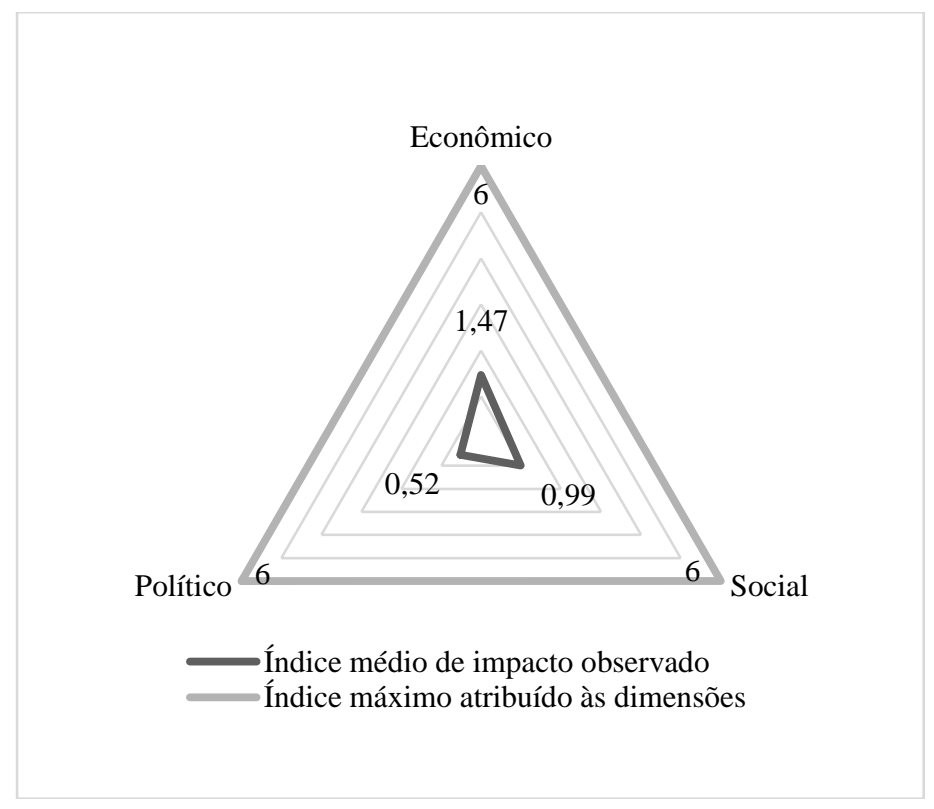

Fonte: elaborado pela autora, a partir dos dados da pesquisa.

As dimensões mais vulneráveis para o empoderamento das mulheres, neste estudo, foram a social e a política (Tabela 1 e Figura 1). As mulheres que se mantêm como "donas de casa" e aquelas que não compartilham a gestão da propriedade e da renda, tendem a não se envolver com agentes sociais externos e a não usufruir das oportunidades sociais.

Embora o processo de empoderamento se concentre inicialmente em nível individual, a tomada de consciência pode ser iniciada a partir do envolvimento das mulheres com outras mulheres (MOSEDALE, 2005; SEN, 2000). Portanto, as participações social e política devem ser pensadas como fatores importantes para o empoderamento das mulheres rurais, em consonância com o desenvolvimento de sua autonomia econômica.

Com relação à dimensão social, o indicador de "desenvolvimento da autoestima" foi o que mais impactou, apresentando pontos positivos, como a ocorrência do sentimento de utilidade e de participação apresentado pelas mulheres. As mulheres se sentiram reconhecidas e participativas na produção, contribuindo para o desenvolvimento do sentimento de realização pessoal e de autoestima.

O indicador "capacidade de agência" também apresentou impacto importante. Isso ocorreu devido ao desenvolvimento das capacidades das mulheres de se tornarem sujeitos 
ativos e não apenas passivos, totalizando $54,4 \%$ das mulheres. Podem-se citar como exemplos: a esposa de um policial militar, que diante da ausência do marido em dias úteis, coube a ela toda a condução das atividades produtivas e negociações; as mulheres divorciadas e viúvas que, ao se verem sozinhas por ocasião do divórcio ou falecimento do marido, recorreram ao Pronaf para a nova fase de suas vidas; as mulheres solteiras que se motivaram para iniciar a vida adulta com a garantia da autonomia econômica, adquirindo propriedade, fazendo contratos de comodato e investindo na terra.

Apesar de o Pronaf não ter sido, nos exemplos citados, o fator que desencadeou a capacidade de agência das mulheres, atuou como ferramenta importante para a realização de suas conquistas. Por outro lado, o acesso ao Programa foi o que despertou a capacidade de agência em algumas das entrevistadas. Após o primeiro acesso ao crédito, parte das mulheres se sentiu empoderada para renegociar dívidas, acessar outras políticas públicas e tomar a frente na gestão da propriedade e da renda, quando os maridos se tornaram apáticos diante das intempéries e variações de mercado.

Entretanto, a dimensão social do empoderamento ainda se mostrou frágil ou em desequilíbrio quando comparada à dimensão econômica. Indicadores como "acesso à assistência técnica", "participação em cursos e capacitações", "desenvolvimento da consciência de gênero" e "mudanças nas relações de gênero" impactaram negativamente o desenvolvimento do poder social. No relato das mulheres, ficou evidente a sua exclusão das áreas de conhecimento técnico gerencial pela pouca atenção dada pelos agentes públicos de extensão rural e pelos consultores privados às necessidades das mesmas.

Com a tradição e naturalização da divisão sexual do trabalho, arraigada no espaço rural (que também impactou negativamente a dimensão econômica), ratificada pela sociedade e pelo estado, por meio da atuação dos agentes políticos e sociais (SCOTT, 1999), as mulheres não vêm, em sua maioria, se conscientizado das questões relativas às relações de gênero, o que impacta diretamente na estagnação dessas relações, não havendo mudanças, mesmo nas famílias em que as mulheres são mais autônomas.

$\mathrm{O}$ fato das mulheres necessitarem sair do espaço privado para o espaço público para acessar o Pronaf, tendo contato com outros agentes sociais, contribuiu como indicador de impacto positivo para a análise da dimensão política. Entretanto, como esse fator atingiu apenas parte das mulheres, os indicadores que mais influenciaram negativamente, 
fragilizando a dimensão política no contexto estudado, foram a participação em cargos diretivos nas organizações e a participação em outras políticas públicas.

Isso é explicado pelo fato de que as mulheres, embora sejam filiadas a alguma forma associativa em 52,7\% dos casos, apenas 17,2\% já ocuparam ou ocupam um cargo na diretoria da organização. Observou-se, portanto, que a organização política, ou a conquista do espaço político pelas mulheres estudadas não ocorreu efetivamente. As mulheres tenderam a se afastar das organizações sociais por não se sentirem ouvidas ou por não se sentirem preparadas, devido ao baixo grau de escolaridade. Nesse contexto, elas desistiram de conquistar o seu direito político de se manifestar, de se candidatar a um cargo eletivo.

Embora as mulheres tenham aumentado seu contato com outros agentes sociais, esse relacionamento não se deu por iniciativa própria, na maior parte dos casos. Esse encontro mulher-mediador social não foi conquistado, mas foi estabelecido por outro. Criou-se a oportunidade de contato dessas mulheres com mediadores (consultores e agentes bancários), com o propósito de beneficiar outra pessoa da família, do sexo masculino. Logo, o contato com agentes sociais não contribuiu para o despertar das mulheres como sujeitos de direitos, resultando na baixa participação das mulheres em outras políticas públicas.

Portanto, o empoderamento é um processo contínuo e não finito, onde não se alcança o poder absoluto, mas um poder relativo e relacional (ROMANO, 2002). As pessoas podem ampliar ou reduzir seu poder em relação a si mesmas quando comparadas épocas diferentes de suas vidas, como antes e após acessar o Pronaf; antes e após terem se divorciado; antes e após terem tido acesso à educação.

Fortalecer as dimensões política e social torna-se uma necessidade para efetivar o processo de empoderamento das mulheres rurais. Como afirmado por Mosedale (2005), não é possível um agente ou uma instituição empoderar um indivíduo, mas estes podem contribuir para a tomada de consciência desse indivíduo e para o desenvolvimento de suas capacidades.

É isso que se espera como consequência das políticas públicas, como as de crédito: fornecer ferramentas para o desenvolvimento das capacidades. Porém, tais capacidades dependem, muitas vezes, da atuação dos mediadores, como facilitadores do acesso às políticas públicas, como incentivadores da inclusão social e como agentes de mudança.

Sen (2000) afirma que não se deve adotar o pretexto de defender valores tradicionais e negligenciar a questão da legitimidade e da necessidade das pessoas afetadas participarem da decisão sobre aquilo que desejam. Mas, a participação requer conhecimento. Nesse ponto, 
reforça-se a importância dos mediadores, em especial os Extensionistas Rurais, no processo de educação não formal e libertadora para as mulheres rurais.

O não envolvimento das mulheres no acesso à informação (social, política, econômico-gerencial, técnico-produtiva) pode mantê-las na obscuridade e reduzir sua participação no processo decisório. Portanto, a ATER, orientada para as questões de gênero, pode contribuir para a transformação do campo, para o desenvolvimento da capacidade de agência das mulheres, do seu reconhecimento como sujeitos de direito e, consequentemente, para a redução das desigualdades de gênero nas famílias e na sociedade como um todo.

\section{Possibilidades e limites do acesso ao Pronaf a partir das dimensões do empoderamento}

Partindo-se da premissa de que as políticas de crédito são importantes ferramentas para o desenvolvimento da autonomia econômica das mulheres (HERNÁNDEZ, 2009) e, a partir dos resultados apresentados, baseado no aporte teórico, resumem-se as possibilidades e limites para o empoderamento de mulheres e sua relação com o desenvolvimento rural.

Dentre os principais fatores que limitaram o desenvolvimento da autonomia das mulheres estudadas, citam-se as relações desiguais de gênero. A construção simbólica dos papéis de gênero e das relações de poder que se estabelecem a partir desses papéis (SCOTT, 1999. KABEER, 1998) afetaram negativamente o desenvolvimento da autonomia das mulheres. Primeiramente, devido às próprias relações intrafamiliares, quando o homem "usa" o nome da mulher para acessar o crédito, sem a devida participação destas; ou, ainda, a impede de investir em uma atividade do seu interesse por demandar a mão de obra da mulher para a atividade principal ou para impedir a possibilidade de autonomia da esposa.

Em nível local, as relações desiguais de gênero estão enraizadas em todas as instituições - igreja, organizações sociais, instituições estatais, empresas - dificultando a real inclusão econômica, produtiva e social das mulheres. As relações desiguais de gênero deram suporte para os demais fatores limitadores do desenvolvimento da autonomia econômica das mulheres, como a baixa autonomia nas decisões.

A maior parte das mulheres estudadas se submetia às decisões dos maridos. Algumas afirmaram compartilhar as decisões, mas admitiram que a palavra final era do marido, pois ele era o "chefe da família". As mulheres solteiras tenderam a se submeter à gestão do pai ou do irmão, permanecendo sem autonomia. Dessa forma, tiveram mais dificuldade em acessar o Pronaf por não terem autonomia para a tomada de decisão. As 
mulheres sem companheiro e sem influência masculina apresentaram autonomia e, consequentemente, capacidade de agência.

A dupla ou a tripla jornada de trabalho também é limitante e está diretamente relacionada à divisão sexual do trabalho advinda das relações desiguais de gênero. $\mathrm{O}$ envolvimento da mulher em atividades agropecuárias resultaria na ampliação da sua jornada de trabalho, haja vista que as atividades domésticas e do entorno não costumam ser divididas de forma igualitária e justa. Aquelas mulheres que já se dedicam às atividades agropecuárias principais, acumulam as atividades domésticas. Assim, o investimento em outras atividades demandaria uma sobrecarga laboral, pois a sua mão de obra não seria dispensada da lavoura principal.

O Pronaf e demais políticas públicas para o meio rural (como os programas de compras governamentais), são pouco divulgados nos municípios estudados, sendo a desinformação um fator limitante. O acesso à informação é limitado, tanto pela baixa capacidade de agência de parte das mulheres, subjugadas à dominação, quanto pela própria discriminação social que as exclui do espaço público, sobretudo dos espaços de decisão.

O medo da perda da lavoura, aliada à falta de informação sobre questões relacionadas às políticas de proteção e de comercialização da produção familiar, bem como das possibilidades de renegociação das dívidas, inibem as mulheres de tomar agência para o investimento em atividades de seu próprio interesse, investindo, portanto, em atividades tradicionais, de domínio masculino, resultando em baixa diversificação das propriedades.

A conduta dos bancos em aprovar somente atividades tradicionais (SILVA, 2019), contribui para a baixa diversificação das atividades rurais, e limita as possibilidades de investimento das mulheres. Embora a maior parte das mulheres tenha demonstrado interesse nas mesmas culturas, elas ainda estão submetidas ao limite de endividamento familiar, geralmente, já comprometido pelos projetos desenvolvidos pelos homens.

A assistência técnica insuficiente e centrada na figura do homem também é um fator limitador. Os mediadores não praticam assistência técnica para a atividade financiada pela mulher e, quando o fazem, está centrada na figura masculina, desvalorizando o conhecimento e capacidade das mulheres, reforçando as hierarquias existentes.

Não foi identificada a prática de uma extensão rural voltada para ações participativas e coletivas que leve à problematização da realidade, conscientização das condições desiguais 
de gênero, planejamento e inclusão produtiva, econômica e social das mulheres. Tal ausência compromete significativamente o processo de empoderamento para o desenvolvimento.

Além disso, identificou-se a falta de interesse dos consultores privados em se envolver em questões de gênero, atendendo exclusivamente às demandas apresentadas e incentivando a aplicação dos recursos em atividades tradicionais e zoneadas, facilitando o processo de operacionalização do crédito, independentemente do envolvimento das mulheres.

A baixa participação social das mulheres é um fator que também está relacionado às relações desiguais de gênero presentes na sociedade. As mulheres tendem a não se envolver em grupos sociais por diversos motivos, tais como a falta de tempo, devido às jornadas de trabalho, por não terem onde deixar os filhos ou a não aceitação dos companheiros (relacionados à divisão sexual do trabalho ou à hierarquia de gênero).

Aquelas mulheres que se filiaram a organizações fizeram-no por facilidades relacionadas aos direitos previdenciários, como no caso do Sindicato dos Trabalhadores Rurais; ou facilidades comerciais, como nas cooperativas de produção; não havendo a sua participação efetiva nesses espaços, comprometendo o empoderamento social e político.

Por outro lado, existem possibilidades e potencialidades nos municípios estudados que podem contribuir para o desenvolvimento das atividades produtivas do interesse das mulheres rurais e para o desenvolvimento de sua autonomia econômica, com vistas ao seu empoderamento e ao desenvolvimento rural.

$\mathrm{O}$ acesso a ATER e ao conhecimento técnico gerencial é um exemplo de possibilidade para o empoderamento das mulheres. A capacitação dos mediadores para atuar com políticas de gênero, priorizando as práticas de ATER voltadas para a mediação das questões de gênero, pode contribuir para a redução das relações desiguais, estimular o desenvolvimento das capacidades das mulheres, tendo como objetivo o seu acesso às diversas políticas públicas, aos espaços políticos e aos mercados, à capacitação e à organização de redes de reciprocidade.

O estabelecimento de parcerias e o planejamento de ações conjuntas entre as organizações sociais, como os sindicatos, as cooperativas, as instituições de ensinoaprendizagem, dentre outros, com a ATER oficial, pode contribuir para a concreção de ações e efetividade dos resultados, evitando as ações desconexas e pulverizadas, que têm apresentado pouco ou nenhum resultado na transformação social no campo. 
A possibilidade de acessar outras políticas públicas também deve ser considerada. Os mercados institucionais, como o Programa de Aquisição de Alimentos (PAA) e o Programa Nacional de Alimentação Escolar (PNAE) ${ }^{6}$, podem contribuir para a inclusão das mulheres nesses mercados, bem como contribuir para a sua participação efetiva nas organizações sociais, a partir da organização da produção para o atendimento a tais políticas.

$\mathrm{O}$ acesso a outros mercados locais e regionais consolidados, como as feiras locais, os mercados do entorno, como também da região metropolitana, pode ser efetivado a partir da profissionalização e do planejamento da produção e da diversificação produtiva, que pode ser acompanhada pela ATER local.

Os meios eficientes de comunicação devem ser considerados como fatores potenciais a serem utilizados. $\mathrm{O}$ acesso à internet já é uma realidade para a população rural, sendo um meio eficiente para divulgação das políticas públicas.

A organização social e política deve ser considerada como uma potencialidade e possibilidade, tendo em vista que os municípios estudados já apresentam experiências com o cooperativismo e associativismo. A mediação, a partir de práticas de pedagogia feminista, pode contribuir para a inclusão social e política das mulheres nas organizações já existentes, bem como na formação de organizações específicas, visando à tomada de consciência de gênero e dando visibilidade e poder de agência às mulheres rurais.

\section{CONSIDERAÇÕES FINAIS}

O desenvolvimento da capacidade de agência das mulheres a partir da sua motivação, o desenvolvimento de redes de reciprocidade, do capital social das mulheres rurais, da ampliação do acesso dessas mulheres às instituições e às oportunidades, resulta no processo de transformação da realidade no campo, com o desenvolvimento de novos símbolos e valores que possam reduzir as relações desiguais de gênero nas famílias rurais e na sociedade como um todo.

O processo emancipatório das mulheres rurais não ocorre facilmente porque é difícil romper com as estruturas tradicionais rurais ancoradas nas heranças do patriarcado. Por

${ }^{6}$ O PAA é um programa de compra governamental de alimentos produzidos pela agricultura familiar, destinando-os às pessoas em situação de insegurança alimentar e nutricional, atendidas por entidades da rede socioassistencial e instituições públicas, além da modalidade de formação de estoque.

No PNAE, está previsto que 30\% do valor repassado pelo governo federal aos municípios para compra da merenda escolar devem ser investidos na compra direta de produtos da agricultura familiar. 
exemplo, o Pronaf Mulher foi criado com o intuito de contribuir para a autonomia econômica das mulheres e dar visibilidade às suas atividades. Mas, os resultados continuam distantes do ideal almejado, pois o crédito oferecido às mulheres está longe de se efetivar como instrumento de empoderamento econômico. A autonomia econômica para as mulheres deve ser pensada de forma diferente do modelo predominante nas políticas de crédito, especialmente quanto à sua operacionalização. Deve-se levar em conta o processo metodológico que considere as especificidades de gênero e os contextos regionais.

A participação das mulheres no Pronaf não deve se limitar ao acesso ao crédito, mas fortalecer sua participação em todas as possibilidades oferecidas pelas políticas públicas para a agricultura familiar. A efetivação da participação das mulheres rurais nas políticas públicas e no processo de desenvolvimento rural depende, em parte, de uma atuação dos agentes de mediação que valorize o papel social e político das mulheres agricultoras, buscando reduzir as relações desiguais de gênero nas famílias e na sociedade como um todo.

Portanto, dentro da perspectiva relacional, as políticas públicas devem apresentar princípios e diretrizes claros de equidade de gênero. A capacitação dos mediadores, para uma atuação pedagógica feminista, também se torna importante para que os princípios e diretrizes das políticas sejam respeitados e implementados, a partir da conscientização dos atores como responsáveis pelo processo de mudança.

Tomando por princípio de que a organização das mulheres pode contribuir para o empoderamento social e de que este pode favorecer as demais dimensões do poder, propõese o estudo do acesso às políticas públicas relacionadas ao desenvolvimento da autonomia econômica nas transformações sociais, entre as mulheres organizadas em associações e cooperativas, no contexto da agricultura familiar.

Propõe-se, ainda, a realização de uma pesquisa-ação participativa, envolvendo a aplicação de métodos da pedagogia feminista em grupos de mulheres rurais, como forma de avaliar o processo de mudança promovido pelas mulheres a partir da tomada de consciência, do desenvolvimento da sua capacidade de agência e das transformações ocorridas nas relações sociais decorrentes da pesquisa-ação.

O empoderamento das mulheres, partindo do acesso ao Pronaf, com vistas ao desenvolvimento de sua autonomia econômica, dificilmente será alcançado, enquanto permanecerem as relações desiguais de gênero na sociedade, enquanto as mulheres não puderem, elas mesmas, decidir sobre as próprias escolhas, sobre o próprio destino. 


\section{REFERÊNCIAS}

BANDEIRA, Lourdes Maria; ALMEIDA, Tânia Mara Campos de. A transversalidade de gênero nas políticas públicas. Revista do Ceam, v. 2, n. 1, p. 35-46, jan./jun. 2013.

BARDIN, Laurence. Análise de conteúdo. Lisboa: Edições 70. 1977. 225p.

BUTTO, A. et al. (orgs). Mulheres rurais e autonomia: formação e articulação para efetivar políticas públicas nos Territórios da Cidadania. Brasília: Ministério do Desenvolvimento Agrário, 2014. 132p.

DEERE, Carmen; LEÓN, Magdalena. Diferenças de gênero em relação a bens: a propriedade fundiária na América Latina. Sociologias, Porto Alegre, ano 5, n ${ }^{\circ} 10$, p. 100153, jul/dez 2002.

DEMATTÊ FILHO, Luiz Carlos et al. Gestão ambiental de atividades rurais no polo de agricultura natural de Ipeúna, SP. RBAS, v.4, n.2, p. 41-48, 2014.

FERNANDES, Sirlei A. Entraves para inclusão de gênero no Pronaf Mulher no meio rural de Santa Catarina. Revista Grifos, n. 34, p. 157-175, 2013.

HAGUETTE, Teresa Maria Frota. Metodologias qualitativas na sociologia. $12 \mathrm{ed}$. Petrópolis, RJ: Vozes, 2010. 223p.

HERNÁNDEZ, Carmen Osório. Política de crédito rural com perspectiva de gênero: um meio de "empoderamento" das mulheres rurais? 2009. $248 \mathrm{f}$. Tese (Doutorado em Desenvolvimento Rural) - Universidade Federal do Rio Grande do Sul, Porto Alegre, 2009.

HERRERA, Karolyna Marin. A jornada interminável: a experiência no trabalho reprodutivo no cotidiano das mulheres rurais. 2019. $227 \mathrm{f}$. Tese (Doutorado em Sociologia Política) - Universidade Federal de Santa Catarina, Florianópolis, 2019.

KABEER, Naila. Women's economic empowerment and inclusive growth: labour markets and enterprise development. SIG Working Paper, v.1, 2012. Disponível em: http://www.idrc.ca/EN/Documents/NK-WEE-Concept-Paper.pdf. Acesso em: 02 fev. 2016. MALHOTRA, A. et al. Measuring Women's Empowerment as a Variable in International Development. Background Paper Prepared for the World Bank Workshop on Poverty and Gender: New Perspectives. Jun, 2002.

MORAES, Lorena Lima de et al. Pedagogia Feminista como processo educativo para a reflexão da política pública de ATER no Nordeste. Interritórios, v.4, n.6, p. 6-29, 2018.

MOSEDALE, Sarah. Assessing women's empowerment: towards a conceptual framework. J. Int. Dev. n. 17, p. 243-257, 2005.

PUTNAM, Robert D. The prosperous community: Social Capital and Public Life. The American Prospect. v. 4, n. 3, p. 1-11, mar. 1993. 
RODRIGUES, Geraldo Stachetti; PIMENTA, Sergio Corrêa; CASARINI, Camila Rodrigues Alves. Ferramentas de avaliação de impactos ambientais e indicadores de sustentabilidade na Embrapa. Jaguariúna: Embrapa Meio Ambiente, n. 105, 2016. 21p. (Documentos).

ROMANO, Jorge O. Empoderamento: recuperando a questão do poder no combate à pobreza. In: ROMANO, Jorge O.; ANTUNES, Marta (orgs.). Empoderamento e direitos no combate à pobreza. Rio de Janeiro: ActionAid Brasil, 2002. 116p.

SARDENBERG, Cecília M.B. Conceituando "Empoderamento" na perspectiva feminista. In: I Seminário Internacional: Trilhas do Empoderamento de Mulheres - Projeto TEMPO', Salvador, Bahia, 2006. Disponível em:

http://www.repositorio.ufba.br/ri/handle/ri/6848. Acesso em: 02 fev. 2019.

SCOTT, Joane Wallach. Género e história. México: Universidad Autónoma de la Ciudad de México, 1999, 337p.

SEN, Amartya. Desenvolvimento como liberdade. São Paulo: Companhia das Letras, 2000.

SILIPRANDI, Emma. Mulheres e agroecologia: transformando o campo, as florestas e as pessoas. Rio de Janeiro: Editora UFRJ, 2015. 352p.

SILVA. Alessandra Maria da. O Pronaf como meio de empoderamento da mulher rural - uma análise da participação feminina e da influência da mediação no estado do Espírito Santo. 2019. 346 f. Tese (Doutorado em Produção Vegetal) - Universidade Estadual do Norte Fluminense Darcy Ribeiro, Campos dos Goytacazes, 2019.

SILVA, Alessandra Maria da. et al. A participação da mulher no Pronaf - uma visão geral do acesso ao programa no Brasil e Regiões. Congresso da Sociedade Brasileira de Administração, Economia e Sociologia Rural. Sober 54. Anais... Maceió-AL: UFAL, 2016.

SPANEVELLO, Rosani Marisa; MATTE, Alessandra; BOSCARDIN, Mariele. Crédito rural na perspectiva das mulheres trabalhadoras rurais da agricultura familiar: uma análise do Programa Nacional de Fortalecimento da Agricultura Familiar (Pronaf). Polis, Revista Latinoamericana, v. 15, n. 44, p. 393-414, 2016.

SPECHT, Analine Almeida. Autonomia crítica das mulheres rurais: a casa pode cair, elas querem voar. 2019. 106 f. Dissertação (Mestrado em Meio Ambiente e Desenvolvimento Rural) - Universidade de Brasília, Brasília, 2019. 